\title{
HERBAL DRINK FORMULATION OPTIMIZATION OF TROLLIUS CHINENSIS BUNGE BY SENSORY FUZZY COMPREHENSIVE EVALUATION
}

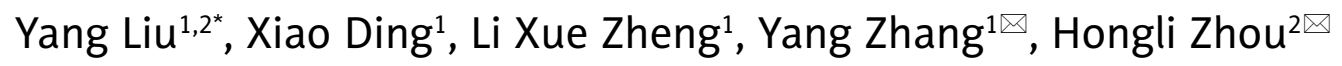 \\ ${ }^{1}$ School of Biology and Food Engineering, Changshu Institute of Technology \\ Nansanhuan road, 215500 Changshu, Jiangsu Province, China \\ ${ }^{2}$ College of Chemical and Pharmaceutical Engineering, Jilin Institute of Chemical Technology \\ Chengde road no. 45, 132022 Jilin, Longtan District, China
}

\begin{abstract}
Background. Trollius chinensis Bunge is a common herbal plant used for pharmaceutical and food resources in China. The dry flowers of Trollius chinensis Bunge are also treated as a traditional Chinese tea for daily drinking, yet the Trollius chinensis Bunge tea will exhibit a bitter taste in a certain concentration range and is not always accepted among consumers. The aim of the study was to design a herbal drink with a good flavor and optimize the formulation.

Materials and methods. Trollius chinensis Bunge was purchased and ground. The sensory fuzzy comprehensive evaluation method and the orthogonal test were applied to optimize the formulation of the Trollius chinensis Bunge herbal drink.

Results. The results showed that the optimum formulation was as follows: an addition amount of Trollius chinensis Bunge extract solution of 30\%; an addition amount of mint extract solution of $4 \%$; an addition amount of liquorice extract solution of 7\%; an addition amount of sugar of 3\%; an addition amount of citric acid of $0.15 \%$. The polysaccharide content decreased with an increase in storage time; the stability of the polysaccharides was not significantly affected by storage temperature $(P>0.05)$. The $\mathrm{pH}$ value of the samples was significantly affected by storage temperature $(P<0.01)$, which was basically unchanged at $4^{\circ} \mathrm{C}$ and $25^{\circ} \mathrm{C}$, and relatively large at $37^{\circ} \mathrm{C}$; the stability of color was significantly affected by temperature $(0.01<P<0.05)$. Conclusion. Sensory fuzzy comprehensive evaluation is an useful evaluation method in optimizing the formulation of a herbal drink. These results provide some theoretical basis for the food product development of Trollius chinensis Bunge.
\end{abstract}

Keywords: Trollius chinensis Bunge, sensory, fuzzy, formulation, optimization

\section{INTRODUCTION}

Trollius chinensis Bunge (T. chinensis Bunge) is a species of a genus in the Ranunculaceae family, most of which grow on grass slopes, loose forests and mountains with an altitude of about 1000-2200 $\mathrm{m}$ (Li and

Funding: This study was funded by the Scientific Research Foundation for Advanced Talents, Changshu Institute of Technology (Grant no. KYZ2018067Q).

\footnotetext{
『zhangyang@cslg.edu.cn, phone 860512 55251562, zhangyangcslg@126.com, phone 86043262185066 *http://orcid.org/0000-0002-9418-6023 
Liu, 2013). It has been reported that there are many active components in the dry flower of $T$. chinensis Bunge, including flavonoids, polysaccharides, organic acids, volatile oil and other components (An et al., 2015; Chen et al., 2017; Yan et al., 2019). Among them, flavonoids account for approximately $16 \%$ of the dried flowers and are considered to be one of the most important active ingredients amongst the dominant compounds it contains (Wang et al., 2008). The dry flowers of $T$. chinensis Bunge are used in traditional Chinese medicine to treat upper respiratory tract diseases, such as pharyngitis, bronchitis and tonsillitis etc. (Guo et al., 2017; Witkowska-Banaszczak, 2015). Many studies have also proved that the dry flower of $T$. chinensis Bunge exhibits significant antioxidant and antibacterial activities (Liu et al., 2013; Lu et al., 2014). In addition, the dry flowers of $T$. chinensis Bunge are also treated as a traditional Chinese tea for daily drinking due to the significant bioactivities in China (Lam et al., 2016). Yet the $T$. chinensis Bunge tea will exhibit a bitter taste in a certain concentration range and is not always accepted among consumers. Therefore, other Chinese herbal foods with a good flavor, such as mint and liquorice, could be added to improve the taste of T. chinensis Bunge tea (Zhang et al., 2016). However, from the literature available, there are few studies about making an herbal drink and optimizing the formulation of $T$. chinensis Bunge.

The sensory evaluation method has widely been applied to evaluate food quality in the development of herbal drinks and food engineering and processes for decades (Skelton, 1984) because it possesses the advantages of strong practicability, high sensitivity, simple operation, cost saving and so on. It has quickly been proved to be a significant technical analysis approach for modern food science and the food industry (Muir, 2007). Unfortunately, it is difficult to obtain objective and credible sensory evaluation results because it is often affected by external factors such as the experience and background of assessors, the evaluation environment and the methods, results analysis methods, etc. (Delahunty and Murray, 2001; Lieb et al., 2018). Fuzzy mathematics, which is widely used and solves many problems, is also a mathematic tool for studying such problems with unclear or ambiguous boundaries in the world. Fuzzy mathematics has been used to assist sensory evaluation in the evaluation of food quality due to the uncertainty and fuzziness of sensory descriptions of color, texture, taste and smell during sensory evaluation. It is proposed in the fuzzy evaluation model (Ioannou et al., 2002; Sakre et al., 2015). The characteristic of fuzzy mathematics is that simple linguistic formulations can be used to present complex system behaviors (Birle et al., 2013). Therefore, the sensory evaluation method combined with Fuzzy mathematics could be utilized to reduce the external factors to get relative objective and credible sensory evaluation results, especially in beverage formulation optimizations in the beverage industry. The aim of the study was to obtain a $T$. chinensis Bunge herbal drink with mint and liquorice and to optimize the formulation using a sensory fuzzy comprehensive evaluation. Furthermore, the product stability was investigated under different storage conditions. These results will provide a scientific basis for its application in functional drinks and the development and utilization of natural products in the food industry, amongst other things.

\section{MATERIALS AND METHODS}

\section{Materials and reagents}

The dry flower of T. chinensis Bunge was purchased from Yakeshi city, Inner Mongolia Autonomous Region, China in January 2019. The liquorice (Glycyrrhiza uralensis Fisch., artificial cultured in 2018), and mint (Mentha haplocalyx Briq., artificial cultured in 2018) leaves were purchased from Chengde city, Hebei province (located in North China, between $36^{\circ} 05^{\prime}-42^{\circ} 40^{\prime} \mathrm{N}$ and $113^{\circ} 27^{\prime}-119^{\circ} 50^{\prime} \mathrm{E}$ ), China in January 2019 . They were ground into a powder with a mill and then passed through a 40-mesh sieve and stored at room temperature. The reagents, including glucose (Tianjin Damao Chemical Reagent Factory, China, CAS: 50-99-7D), citric acid (Tianjin Damao Chemical Reagent Factory, China, 77-92-9), white sugar (Ganzhou Yunshen Agricultural Development Co., Ltd., China) etc., were all analytical grade.

\section{Extraction method of material}

All the material was extracted using the distilled water extraction method, taking the polysaccharide as the main component. According to the previous research (Liu et al., 2012), the extraction parameters of T. chinensis Bunge were as follows: material liquid ratio 
1:60 (g:mL), temperature $80^{\circ} \mathrm{C}$, extraction time $3 \mathrm{~h}$, the extraction solution was stirred with a magnetic stirrer (Zhengzhou biochemical instrument Co., Ltd., China, SZCL-3B) and then filtered. From the literature available (You et al., 2014), the extraction parameters of liquorice were as follows: material liquid ratio 1:30 (g:mL), temperature $80^{\circ} \mathrm{C}$, extraction time $3 \mathrm{~h}$. The extraction solution was stirred with a stirrer and then filtered. The extraction parameters of mint were as follows (Li et al., 2014): material liquid ratio 1:25 (g:mL), temperature $100^{\circ} \mathrm{C}$, extraction time $1 \mathrm{~h}$. The extraction solution was stirred with a stirrer and then filtered. All the filtrate was reserved at $4^{\circ} \mathrm{C}$ for the experiment.

\section{Sensory evaluation of drink with different addition amounts of $T$. chinensis Bunge extraction solution}

Sensory scoring was carried out on the drink with different addition amounts of $T$. chinensis Bunge extraction solution. Panelists (10 persons, 5 male, 5 female, 20-30 years of age) were selected among staff and students at the Changshu Institute of Technology and trained according to GB/T 16291.1 (2012). Sensory score and criterion are described in Table 1 and Table 2 . The sensory criterion was divided into 4 grades of taste, color, aroma and state. The addition amount of the $T$. chinensis Bunge extraction solution was set

Table 1. The sensory evaluation score

\begin{tabular}{|c|c|c|c|c|c|}
\hline \multirow{2}{*}{ Target } & \multicolumn{4}{|c|}{ Standard } & \multirow{2}{*}{ Score } \\
\hline & distinction & good & average & poor & \\
\hline Taste & $(76-100)$ & $(51-75)$ & $(26-50)$ & $(1-25)$ & \\
\hline Coloration & $(76-100)$ & $(51-75)$ & $(26-50)$ & $(1-25)$ & \\
\hline Status & $(76-100)$ & $(51-75)$ & $(26-50)$ & $(1-25)$ & \\
\hline Aroma & $(76-100)$ & $(51-75)$ & $(26-50)$ & $(1-25)$ & \\
\hline Suggestion & & & & average & \\
\hline Date & & & evaluator & & \\
\hline
\end{tabular}

Table 2. The criterion of sensory evaluation

\begin{tabular}{|c|c|c|c|c|}
\hline & Coloration & Taste & Aroma & Status \\
\hline $\begin{array}{l}\text { Distinction } \\
(76-100)\end{array}$ & $\begin{array}{l}\text { The color of the prod- } \\
\text { uct is light yellow, } \\
\text { pure and uniform. }\end{array}$ & $\begin{array}{l}\text { The taste is moderate, soft } \\
\text { and refreshing, there is no } \\
\text { bitterness. }\end{array}$ & $\begin{array}{l}\text { The aroma is fresh and } \\
\text { pleasant, harmonious } \\
\text { and uniform. }\end{array}$ & $\begin{array}{l}\text { It is clear, transparent } \\
\text { without impurities, } \\
\text { and good fluidity. }\end{array}$ \\
\hline $\begin{array}{l}\text { Good } \\
(51-75)\end{array}$ & $\begin{array}{l}\text { The color is uniform } \\
\text { and light yellow. }\end{array}$ & $\begin{array}{l}\text { The taste is slightly strong } \\
\text { or light, soft and refreshing. }\end{array}$ & $\begin{array}{l}\text { The aroma is slightly } \\
\text { strong or light } \\
\text { and harmonious. }\end{array}$ & $\begin{array}{l}\text { It is clear and transparent, } \\
\text { free of impurities and has } \\
\text { good fluidity. }\end{array}$ \\
\hline $\begin{array}{l}\text { Medium } \\
(26-50)\end{array}$ & $\begin{array}{l}\text { The color is uniform } \\
\text { with a little impurity. }\end{array}$ & $\begin{array}{l}\text { The taste is strong or light, } \\
\text { there is a little bitterness. } \\
\text { The sour and sweet taste } \\
\text { are not appropriate. }\end{array}$ & $\begin{array}{l}\text { The aroma is light, } \\
\text { with a slight odor, } \\
\text { and it is not harmonious. }\end{array}$ & $\begin{array}{l}\text { It is slightly clear } \\
\text { and transparent, } \\
\text { with impurities } \\
\text { and fluidity. }\end{array}$ \\
\hline $\begin{array}{l}\text { Poor } \\
(1-25)\end{array}$ & $\begin{array}{l}\text { The color is extremely } \\
\text { nonuniform and dark. }\end{array}$ & $\begin{array}{l}\text { The taste is very strong or } \\
\text { is not obvious, the bitterness } \\
\text { is heavy. The sour and sweet } \\
\text { taste are not appropriate. }\end{array}$ & $\begin{array}{l}\text { The aroma is light } \\
\text { or strong and } \\
\text { is not pleasant. }\end{array}$ & $\begin{array}{l}\text { It is not clear or transparent } \\
\text { enough, with many impuri- } \\
\text { ties and poor fluidity. }\end{array}$ \\
\hline
\end{tabular}


as $10 \%, 20 \%, 30 \%, 40 \%$ and $50 \%$, the number of samples was 5 , and the sample temperature was $20^{\circ} \mathrm{C}$. The samples were encoded with random 3-digit numbers; each sample was submitted twice to each panelist; purified water was used to cleanse the mouth between samples (Chen et al., 2016). The sensory tests were conducted in a sensory analysis laboratory equipped with individual booths (room temperature $24^{\circ} \mathrm{C}$, relative humidity $50 \%$ and combined artificial light with color temperature of $6500 \mathrm{~K}$ ), designed according to ISO 8589 (1988). The laboratory was located in room 309, Duxing Building, Changshu Institute of Technology. The session was conducted at most twice a day and took about $2 \mathrm{~h}$ each time. The addition amounts of other ingredients were as follows: liquorice $5 \%$; mint extract $2.5 \%$; cyclamate $0.05 \%$; sugar $2.5 \%$; citric acid $0.25 \%$; liquorice $5 \%$.

\section{The sensory fuzzy comprehensive evaluation method}

Establishment of evaluation domain. The number of samples was 29 and other sensory evaluation conditions were the same as above. Evaluation domain refers to a set of indicators that best reflect the quality of the food, usually expressed by $U=\left\{u_{1}, u_{2}, u_{3}, \ldots, u_{N}\right\}$, with $u$ representing the evaluation indicators of the evaluated food. The evaluation indicators are taste, color, aroma and state; they are represented by $u_{1}, u_{2}$, $u_{3}$ and $u_{4}$, respectively. The evaluation domain of the herbal drink is set as $U=\left\{u_{1}, u_{2}, u_{3}, u_{4}\right\}$ (Debjani et al., 2013; Mukhopadhyay et al., 2013).

Establishment of comment domain. Comment domain refers to a complete collection of all evaluation results and feedback information after sensory evaluation of the food by all assessors. The process of establishing the evaluation domain is actually the process of determining the level of evaluation results. It is usually expressed as $V=\left\{v_{1}, v_{2}, v_{3}, \ldots, v_{N}\right\}$. Vindicates the corresponding evaluation grade or score. In this experiment, $V$ represents the evaluation level. The evaluation results of herbal drink are divided into four grades of excellent, good, medium and poor, which are represented by $v_{1}, v_{2}, v_{3}$ and $v_{4}$, respectively. The comment domain of the herbal drink is set as $V=\left\{v_{1}, v_{2}, v_{3}, v_{4}\right\}$ (Hmar et al., 2017).
Setting the weight vector. Each evaluation indicator we measured has a different influence on the taste of the sample, so we can determine a weight vector according to the weight value of each indicator, which is $A=\left\{a_{1}, a_{2}, a_{3}, \ldots, a_{n}\right\}$. A corresponds to $U$, and $A$ is a fuzzy subset of $U$. The weight vectors were set as coloration, taste, aroma and status. Based on the experience, the assessors allocated 10 points to four evaluation indicators in the table and determined the weight vector after statistical analysis (Sakre, 2015).

Establishment of the fuzzy matrix. According to the evaluation results of the assessors, the fuzzy matrix was determined. The fuzzy matrix is expressed as $R=\left(r_{\mathrm{ij}}\right)$, where $r_{\mathrm{ij}}$ represents the ratio of the number of people who chose this grade in the matrix to the total number of assessors (Sinija and Mishra, 2011).

\section{Calculation of the comprehensive membership de-} gree and comprehensive score. The calculation of the comprehensive membership degree of the samples is expressed as the calculation of the weight vector and fuzzy matrix by the matrix multiplication, $Y=A \cdot R=$ $\left(b_{1}, b_{2}, b_{3}, \ldots, b_{n}\right)$. The calculation formula of the comprehensive score is $H=\Sigma j b$. The comprehensive score is between 1-4; the 1,2, 3 and 4 represent excellent, good, medium and poor, respectively. If the score is between 3 and 4 , or the product score is close to 3 , the product tends to be medium. If the score is between 1 and 2 , or the product score is close to 1 , the product tends to be excellent.

Orthogonal experimental design for herbal drink. Taking the addition amount of the liquorice extract, mint extract, sugar and citric acid as factors, $L_{9}\left(3^{4}\right)$ orthogonal experiment was designed to optimize the

Table 3. Factor level of orthogonal experiment

\begin{tabular}{lllll}
\hline & A & B & C & D \\
\hline 1 & 3 & 5 & 2.5 & 0.15 \\
2 & 3.5 & 6 & 3 & 0.2 \\
3 & 4 & 7 & 3.5 & 0.25 \\
\hline
\end{tabular}

A - amount of mint, \%, B - amount of liquorice, $\%, C$ - amount of sugar, $\%, \mathrm{D}-$ amount of citric acid, $\%$. 
herbal drink formula and the sensory fuzzy comprehensive score was used as the standard of optimization. The single factor design is exhibited in Table 3. The general addition amount of raw and subsidiary materials was: T. chinensis Bunge extract 30\%; licorice extract $5 \%$; mint extract $2.5 \%$; sugar $2.5 \%$; citric acid $0.25 \%$; cyclamate $0.05 \%$.

Determination of polysaccharide. The phenolsulfuric acid (PSA) method was used to determine the polysaccharide content of the herbal drink $(\mathrm{Hu}$ et al., 2018). Firstly, the glucose standard curve was analyzed. Glucose dried to a constant weight $\left(105^{\circ} \mathrm{C}\right)$ of $50.00 \mathrm{mg}$ was accurately weighed and diluted into a $100 \mathrm{~mL}$ volumetric flask to prepare the glucose standard solution. Solutions of $0.0 \mathrm{~mL}, 4.0 \mathrm{~mL}$, $8.0 \mathrm{~mL}, 12.0 \mathrm{~mL}, 16.0 \mathrm{~mL}$ and $20.0 \mathrm{~mL}$ were aspirated and diluted into a $100 \mathrm{~mL}$ volumetric flask to obtain different concentrations of glucose diluent, respectively. The above diluent of $0.5 \mathrm{~mL}$ was aspirated into a $10.0 \mathrm{~mL}$ test tube, then $1.0 \mathrm{~mL}$ of $5 \%$ phenol was added, and concentrated sulfuric acid of $5.0 \mathrm{~mL}$ was immediately added. The solution was shaken well and left to react in a $40^{\circ} \mathrm{C}$ water bath for 30 minutes, and then put in a cold-water bath for 10 minutes. The absorbance was measured under the wavelength of $490 \mathrm{~nm}$ to determine the glucose content. Taking the glucose content as abscissa and the absorbance value as ordinate, the glucose standard curve was obtained. Secondly, the polysaccharides in the herbal drink was determined. A sample solution of $5.0 \mathrm{~mL}$ was added to a test tube of $30.0 \mathrm{~mL}$, then $1.0 \mathrm{~mL}$ of $5 \%$ phenol was added and concentrated sulfuric acid of $5.0 \mathrm{~mL}$ was immediately added. The test tube was shaken well and left to react in a $40^{\circ} \mathrm{C}$ water bath for $30 \mathrm{~min}$ and then put in a cold-water bath for $10 \mathrm{~min}$. The absorbance was measured at $490 \mathrm{~nm}$. According to the measured absorbance value and the standard curve equation of glucose, the content of polysaccharides was calculated. The standard curve of glucose is shown in Figure 1. The linear regression equation was:

$$
y=5.7729 x+0.0005 ; R^{2}=0.9994
$$

It can be seen from the figure that the correlation coefficient of the linear regression equation is 0.9994 , which proved the correlation was good in the content

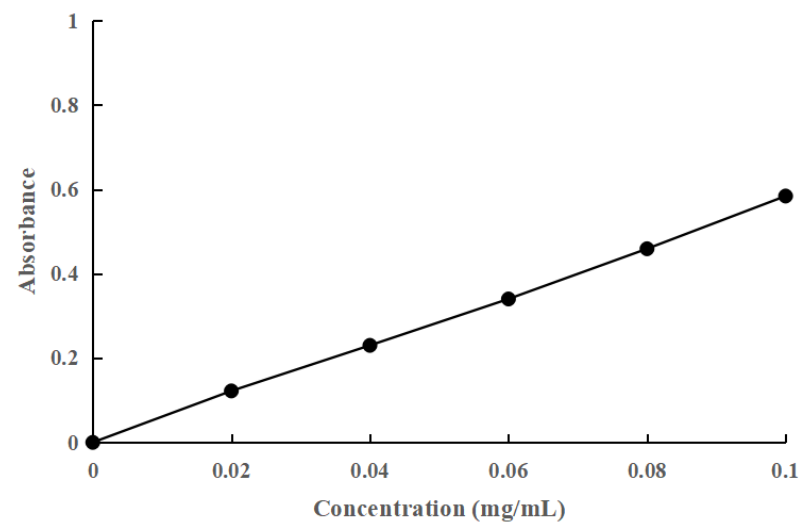

Fig. 1. The standard curve of glucose

range of $0-0.12 \mathrm{mg} / \mathrm{mL}$. The content of polysaccharides was calculated according to the linear regression equation.

Processing technology of the herbal drink. The prepared sample was filtered, clarified and homogenized (High pressure homogenizer, SRH 60-70, Shanghai shenlu homogenizer Co., Ltd., China), and then sterilized and sealed. The pasteurization method was used to sterilize the herbal drink, at $80^{\circ} \mathrm{C}$ with a sterilization time of 30 minutes. This method is easy to operate and does little damage to the nutrients in the beverage (Cifelli et al., 2010). Finally, the sample was sealed using a small beverage filling machine (Huili high cup sealing machine, WY-802D, Foshan Nanhai Bofei mechanical and Electrical Equipment Co., Ltd., China) in a sterile environment ( $\mathrm{Li}$ et al., 2017).

Stability evaluation of the herbal drink. After sterilization and sealing, the samples were placed at $4^{\circ} \mathrm{C}$, $25^{\circ} \mathrm{C}$ and $37^{\circ} \mathrm{C}$ for one month. The polysaccharide content was determined by PSA, the $\mathrm{pH}$ value was determined by acidometer (PH-100, Bangxi Instrument Technology Co., Ltd., China), and the color change was measured by the absorbance under a wavelength of $360 \mathrm{~nm}$ (Gül et al., 2017). In this experiment, according to the national standard (GB 4789.2-3-2016 of China), the total number of colonies and Escherichia coli were detected as microbial indicators. 


\section{RESULTS AND DISCUSSION}

\section{Determination of the addition amount} of the $T$. chinensis Bunge extraction solution

The addition amount of the T. chinensis Bunge extraction solution was directly determined by sensory evaluation, because it was not designed as a single factor. From the results of the sensory evaluation observed in Table 4, The addition amount was set as $30 \%$.

Table 4. Sensory evaluation results of addition amount with T. chinensis Bunge extraction solution

\begin{tabular}{lccccc}
\hline Amount & $10 \%$ & $20 \%$ & $30 \%$ & $40 \%$ & $50 \%$ \\
\hline Grade & poor & good & excellent & medium & poor \\
\hline
\end{tabular}

\section{Evaluation of single factor using the sensory} fuzzy comprehensive scoring method Weight vector setting results of sensory evaluation. From the sensory evaluation, the results of the weight vector setting are shown in Table 5. The weight of the herbal drink was taste $43 \%$, color $20 \%$, aroma $18 \%$ and status $19 \%$, the weight vector $A=(0.43,0.2$, $0.18,0.19)$.

Table 5. The score of the weight vector setting survey

\begin{tabular}{|c|c|c|c|c|c|c|c|c|c|c|c|c|}
\hline \multirow{2}{*}{ Target } & \multicolumn{10}{|c|}{ Evaluator } & \multirow{2}{*}{$\begin{array}{l}\text { Total } \\
\text { point }\end{array}$} & \multirow{2}{*}{$\begin{array}{c}\text { Weight } \\
\%\end{array}$} \\
\hline & 1 & 2 & 3 & 4 & 5 & 6 & 7 & 8 & 9 & 10 & & \\
\hline Taste & 4 & 4 & 4 & 4 & 4 & 5 & 5 & 5 & 4 & 4 & 43 & 43 \\
\hline Color & 1 & 2 & 2 & 3 & 2 & 2 & 2 & 2 & 2 & 2 & 20 & 20 \\
\hline Aroma & 2 & 1 & 2 & 1 & 3 & 2 & 2 & 1 & 3 & 1 & 18 & 18 \\
\hline Status & 3 & 3 & 2 & 2 & 1 & 1 & 1 & 2 & 1 & 3 & 19 & 19 \\
\hline
\end{tabular}

Calculation results of the sensory fuzzy comprehensive scoring method. The assessor's choices of different grades for the single factor test of mint (101105), liquorice (201-205), sugar (301-305) and citric acid (401-405) are shown in Table 6.
Table 6. Summary of evaluator choices of different grades for single factor test

\begin{tabular}{|c|c|c|c|c|c|c|c|c|c|c|c|c|c|c|c|c|}
\hline \multirow{2}{*}{ No. } & \multicolumn{4}{|c|}{ Taste } & \multicolumn{4}{|c|}{ Coloration } & \multicolumn{4}{|c|}{ Status } & \multicolumn{4}{|c|}{ Aroma } \\
\hline & A & B & $\mathrm{C}$ & D & A & B & $\mathrm{C}$ & D & A & B & C & D & A & B & C & D \\
\hline 101 & 1 & 2 & 7 & 0 & 8 & 2 & 0 & 0 & 5 & 4 & 1 & 0 & 4 & 5 & 1 & 0 \\
\hline 102 & 1 & 7 & 2 & 0 & 9 & 1 & 0 & 0 & 7 & 3 & 0 & 0 & 5 & 4 & 1 & 0 \\
\hline 103 & 0 & 5 & 5 & 0 & 7 & 3 & 0 & 0 & 6 & 1 & 3 & 0 & 4 & 4 & 2 & 0 \\
\hline 104 & 3 & 3 & 4 & 0 & 9 & 1 & 0 & 0 & 7 & 3 & 0 & 0 & 5 & 2 & 3 & 0 \\
\hline 105 & 0 & 7 & 3 & 0 & 8 & 2 & 0 & 0 & 8 & 2 & 0 & 0 & 7 & 3 & 0 & 0 \\
\hline 201 & 4 & 6 & 0 & 0 & 9 & 1 & 0 & 0 & 9 & 1 & 0 & 0 & 7 & 3 & 0 & 0 \\
\hline 202 & 4 & 6 & 0 & 0 & 8 & 2 & 0 & 0 & 8 & 2 & 0 & 0 & 8 & 2 & 0 & 0 \\
\hline 203 & 4 & 6 & 0 & 0 & 7 & 2 & 1 & 0 & 6 & 4 & 0 & 0 & 6 & 4 & 0 & 0 \\
\hline 204 & 3 & 7 & 0 & 0 & 7 & 3 & 0 & 0 & 7 & 3 & 0 & 0 & 7 & 3 & 0 & 0 \\
\hline 205 & 3 & 6 & 1 & 0 & 7 & 3 & 0 & 0 & 6 & 3 & 1 & 0 & 8 & 2 & 0 & 0 \\
\hline 301 & 2 & 4 & 3 & 1 & 6 & 4 & 0 & 0 & 6 & 2 & 2 & 0 & 4 & 5 & 1 & 0 \\
\hline 302 & 1 & 6 & 2 & 0 & 5 & 2 & 3 & 0 & 4 & 2 & 4 & 0 & 3 & 6 & 1 & 0 \\
\hline 303 & 2 & 5 & 3 & 0 & 6 & 4 & 0 & 0 & 5 & 2 & 3 & 0 & 3 & 7 & 0 & 0 \\
\hline 304 & 3 & 6 & 1 & 0 & 6 & 4 & 0 & 0 & 6 & 3 & 1 & 0 & 4 & 5 & 1 & 0 \\
\hline 305 & 5 & 3 & 2 & 0 & 7 & 3 & 0 & 0 & 7 & 2 & 1 & 0 & 4 & 5 & 1 & 0 \\
\hline 401 & 7 & 2 & 1 & 0 & 10 & 0 & 0 & 0 & 8 & 1 & & 0 & 9 & 1 & 0 & 0 \\
\hline 402 & 7 & 3 & 0 & 0 & 9 & 1 & 0 & 0 & 9 & 1 & 0 & 0 & 8 & 2 & 0 & 0 \\
\hline 403 & 5 & 5 & 0 & 0 & 9 & 1 & 0 & 0 & 9 & 1 & 0 & 0 & 8 & 2 & 0 & 0 \\
\hline 404 & 4 & 6 & 0 & 0 & 8 & 2 & 0 & 0 & 9 & 1 & 0 & 0 & 8 & 2 & 0 & 0 \\
\hline 405 & 2 & 8 & 0 & 0 & 6 & 4 & 0 & 0 & 9 & 1 & 0 & 0 & 7 & 3 & 0 & 0 \\
\hline
\end{tabular}

A - excellent, B - good, C - medium, D - poor.

No. 101 was taken as an example to calculate the sensory fuzzy comprehensive score. The specific calculation steps are as follows:

Fuzzy matrix:

$$
R_{101}=\left(r_{\mathrm{ij}}\right)=\left[\begin{array}{cccc}
\frac{1}{10} & \frac{2}{10} & \frac{7}{10} & 0 \\
\frac{8}{10} & \frac{2}{10} & 0 & 0 \\
\frac{5}{10} & \frac{4}{10} & \frac{1}{10} & 0 \\
\frac{4}{10} & \frac{5}{10} & \frac{1}{10} & 0
\end{array}\right]
$$


Wight vector:

$$
A=(0.43,0.2,0.18,0.19)
$$

Comprehensive membership degree:

$$
Y=A \cdot R_{101}=\left(b_{1}, b_{2}, b_{3}, \ldots, b_{n}\right)=
$$$$
(0.43,0.2,0.18,0.19)
$$

$$
Y=(0.37,0.292,0.338,0)
$$

Sensory fuzzy comprehensive score:

$$
\begin{gathered}
H=\Sigma j b_{j}=1 \times 0.37+2 \times 0.292+3 \times 0.338+4 \times 0 \\
=1.968
\end{gathered}
$$

The calculation of the other samples is the same.

The effect of single factors on the sensory fuzzy comprehensive score. The effect of single factors on the sensory fuzzy comprehensive score are expressed

A

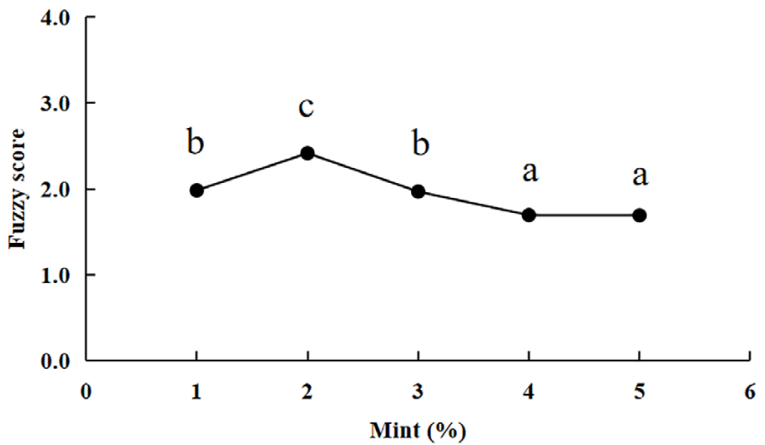

C

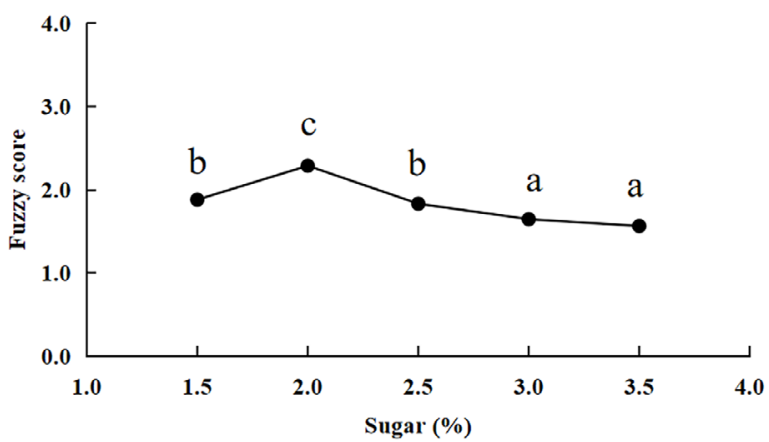

in Figure 2. The lower the score, the better the sensory effect of the beverage. It can be seen from Figure 2A that the score showed a trend of increasing first and then decreasing, and the score is the lowest in the addition amount of $4 \%(P<0.05)$. Therefore, the addition amount of the mint extract solution was determined as $4 \%$. In addition, the effect of the addition amount with liquorice and sugar on the score exhibited a similar trend to that of mint from Figure $2 B$ and Figure $2 C$. The addition amounts of liquorice extract solution and sugar were $6 \%(P<0.05)$ and $3.5 \%(P<0.05)$, respectively. In contrast, the score showed a trend of decreasing first and then increasing in Figure 2D, and the optimum addition amount of citric acid was $0.2 \%(P<0.05)$.

\section{Analysis of orthogonal test results}

The result of the orthogonal test is displayed in Table 7 . The closer the score is to 1 , the better the product

B

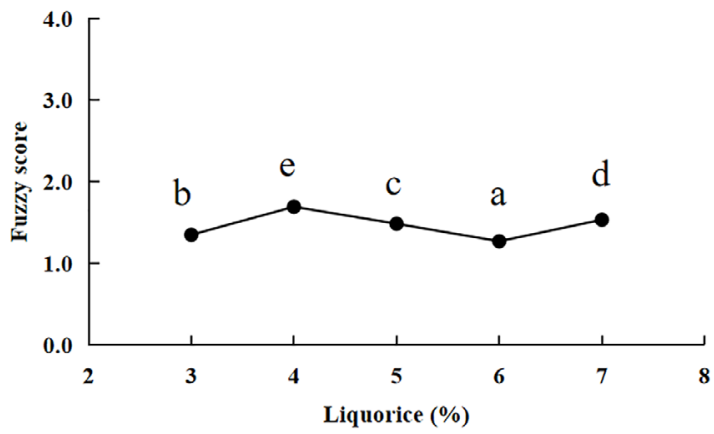

D

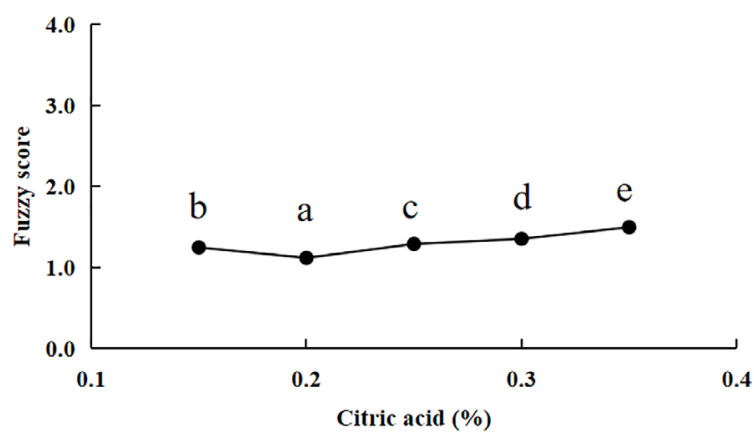

Fig. 2. Effect of single factors on the sensory fuzzy comprehensive score (different letters refers to $p<0.05$ ) 
Liu, Y., Ding, X., Zheng, L. X., Zhang, Y., Zhou, H. (2020). Herbal drink formulation optimization of Trollius chinensis Bunge by sensory fuzzy comprehensive evaluation. Acta Sci. Pol. Technol. Aliment., 19(2), 185-194. http://dx.doi.org/10.17306/J.AFS.2020.0776

Table 7. Orthogonal test results

\begin{tabular}{llllll}
\hline & \multicolumn{1}{c}{$\mathrm{A}$} & $\mathrm{B}$ & $\mathrm{C}$ & $\mathrm{D}$ & $\begin{array}{c}\text { Fuzzy } \\
\text { score }\end{array}$ \\
\hline 1 & 3 & 5 & 2.50 & 0.15 & 1.200 \\
2 & 3 & 6 & 3 & 0.20 & 1.224 \\
3 & 3 & 7 & 3.50 & 0.25 & 1.428 \\
4 & 3.50 & 5 & 3 & 0.25 & 1.412 \\
5 & 3.50 & 6 & 3.50 & 0.15 & 1.686 \\
6 & 3.50 & 7 & 2.50 & 0.20 & 1.381 \\
7 & 4 & 5 & 3.50 & 0.20 & 1.211 \\
8 & 4 & 6 & 2.50 & 0.25 & 1.254 \\
9 & 4 & 7 & 3 & 0.15 & 1.192 \\
$k_{1}$ & 1.284 & 1.274 & 1.279 & 1.360 & \\
$k_{2}$ & 1.493 & 1.388 & 1.276 & 1.272 & \\
$k_{3}$ & 1.219 & 1.334 & 1.442 & 1.364 & \\
$\mathrm{R}$ & 0.274 & 0.114 & 0.166 & 0.092 & \\
\hline
\end{tabular}

$\mathrm{A}$ - amount of mint extract, \%, B - amount of liquorice extract, $\%, \mathrm{C}-$ amount of sugar extract, \%, D - amount of lemon extract, $\%$.

is. Due to the $R$ value, the influence order of several single factors on the results is $A>C>B>D$. After comparing the $k$ value, the optimum formulation was $A 3 B 1 C 2 D 2$, and the addition amounts of mint extract solution, liquorice extract solution, sugar and citric acid were $4 \%, 5 \%, 3 \%$ and $0.2 \%$, respectively. There is no experiment group in the orthogonal test. Meanwhile, the 9th group in the test has the lowest fuzzy score, and the addition amounts of mint extract solution, liquorice extract solution, sugar and citric acid were $4 \%, 7 \%, 3 \%$ and $0.15 \%$, respectively. Therefore, a verified test needed to be carried out. After the verified test, the score of the $A 3 B 1 C 2 D 2$ group was 1.225, which is greater than that of the 9th group (1.192). Finally, the 9th group was chosen as the optimum formulation. The optimum formulation was as follows: an addition amount of $T$. chinensis Bunge extract solution of $30 \%$; an addition amount of mint extract solution of $4 \%$; an addition amount of liquorice extract solution of $7 \%$; an addition amount of sugar of $3 \%$; an addition amount of citric acid of $0.15 \%$.

\section{Stability evaluation of the herbal drink}

The stability of the polysaccharide content, $\mathrm{pH}$ value and color change were evaluated under the storage conditions of $4^{\circ} \mathrm{C}, 25^{\circ} \mathrm{C}$ and $37^{\circ} \mathrm{C}$ for one month, as is shown in Figure 3.
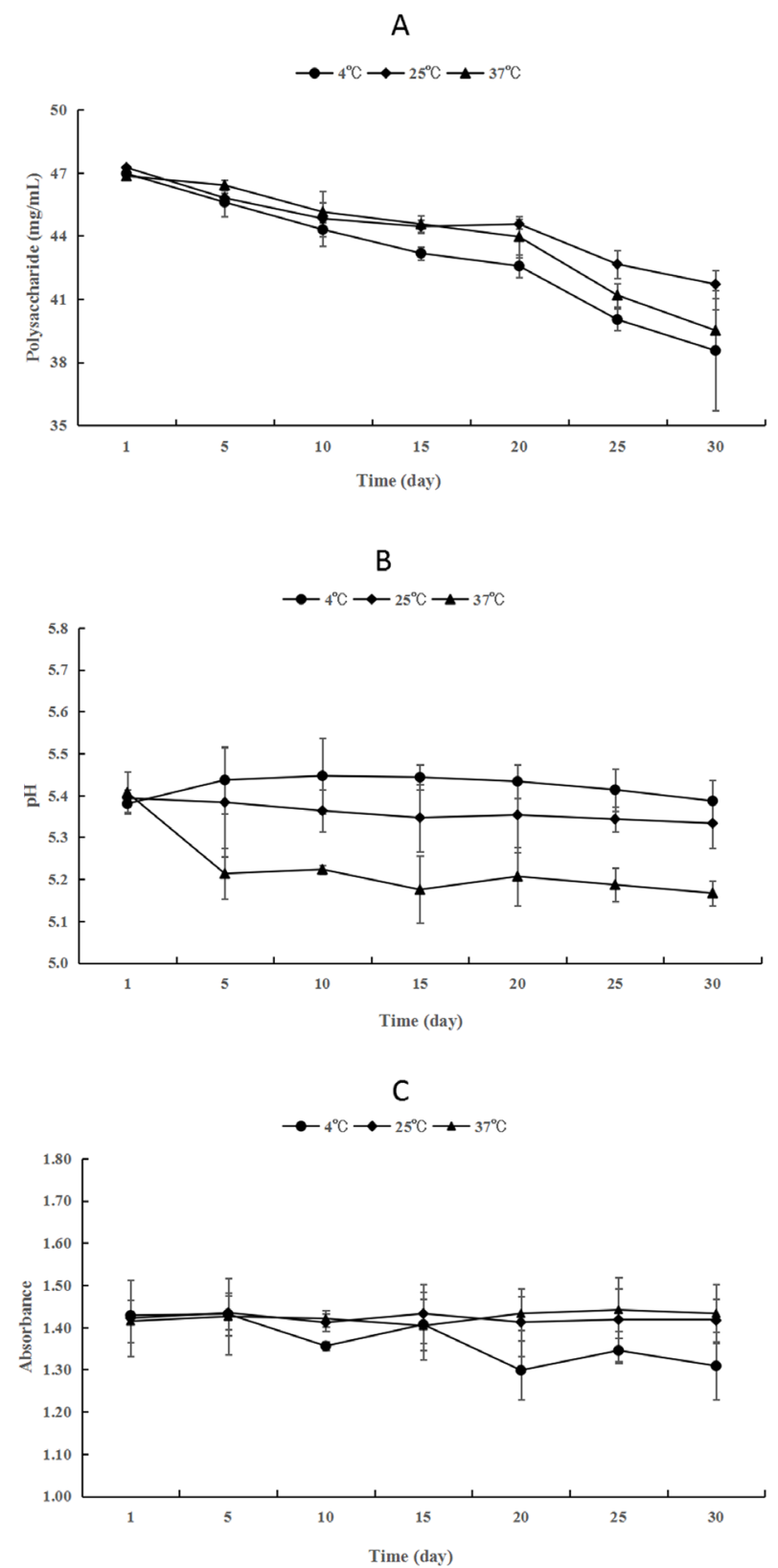

Fig. 3. Stability of herbal drink under different storage temperatures 
The polysaccharide content decreased with an increase in storage time (Fig. 3A), and the stability of the polysaccharides was not significantly affected by storage temperature $(P>0.05)$. The $\mathrm{pH}$ value of the sample was significantly affected by storage temperature $(P<0.01)$, which was basically unchanged at $4^{\circ} \mathrm{C}$ and $25^{\circ} \mathrm{C}$, and relatively large at $37^{\circ} \mathrm{C}$ (Fig. 3B). This phenomenon may demonstrate that the $\mathrm{pH}$ value is affected by a higher temperature. The stability of the color was significantly affected by temperature $(0.01<P<$ 0.05) (Fang et al., 2007), which was relatively more stable at $4{ }^{\circ} \mathrm{C}$ and $25^{\circ} \mathrm{C}$ than at $37^{\circ} \mathrm{C}$ (Fig. 3C). These results suggest that the herbal drink was suitably stored under $4^{\circ} \mathrm{C}$ or at room temperature. The quality reduction of the herbal dink occurs at a high temperature.

\section{Microbiological test results}

The number of the Escherichia coli group was detected in the sample according to GB 4789.3 (2016). The total number of bacterial colonies of the sample was $60 \mathrm{CFU} / \mathrm{mL}$ according to GB 4789.2 (2016) of China. All the samples meet the requirements of GB 7101 (2015) of the China Standard for the microbial limit of beverages.

\section{CONCLUSION}

In this paper, the sensory fuzzy comprehensive evaluation method was applied to optimize the formulation of the T. chinensis Bunge herbal drink. The addition amounts of mint extract solution, liquorice extract solution, sugar and citric acid were designed as single factors, and the optimum formulation was optimized using the orthogonal test. The optimum formulation was as follows: an addition amount of $T$. chinensis Bunge extract solution of $30 \%$; an addition amount of mint extract solution of 4\%; an addition amount of liquorice extract solution of 7\%; an addition amount of sugar of $3 \%$; an addition amount of citric acid of $0.15 \%$. The stability of the polysaccharides was not significantly affected by storage temperature $(P>0.05)$, meanwhile, the $\mathrm{pH}$ value $(P<0.01)$ and the stability of the color $(0.01<P<0.05)$ were significantly affected by temperature. The formulation of a herbal drink with a good flavor was obtained and can be provided to consumers. These results provide some theoretical basis for the development of $T$. chinensis Bunge as a food product.

\section{ACKNOWLEDGEMENTS}

The authors express their gratitude to the Jilin Institute of Chemical Technology for data collection.

\section{REFERENCES}

An, F., Wang, S., Tian, Q., Zhu, D. (2015). Effects of orientin and vitexin from Trollius chinensis on the growth and apoptosis of esophageal cancer EC-109 cells. Oncol. Lett., 10(4), 2627-2633. https://doi.org/10.3892/ol.2015.3618

Birle, S., Hussein, M. A., Becker, T. (2013). Fuzzy logic control and soft sensing applications in food and beverage processes. Food Control, 29(1), 254-269. https:// doi.org/10.1016/j.foodcont.2012.06.011

Chen, F., Zhang, Q., Mo, K., Fei, S., Gu, H., Yang, L. (2017). Optimization of ionic liquid-based homogenate extraction of orientin and vitexin from the flowers of Trollius chinensis and its application on a pilot scale. Sep. Purif. Technol., 175, 147-157. https://doi.org/10.1016/j.seppur.2016.10.062

Chen, M. L., Quan, Y., Zhan, Y. H. (2016). Food sensory evaluation. Nanjing, China: Nanjing University Press.

Cifelli, C. J., Maples, I. S., Miller, G. D. (2010). Pasteurization: implications for food safety and nutrition. Nutr. Today, 45(5), 207-213. https://doi.org/10.1097/ NT.0b013e3181f1d689

Debjani, C., Das, S., Das, H. (2013). Aggregation of sensory data using fuzzy logic for sensory quality evaluation of food. J. Food Sci. Technol., 50(6), 1088-1096. https:// doi.org/10.1007/s13197-011-0433-x

Delahunty, C. M., Murray, J. M. (2001). Descriptive sensory analysis: past, present and future. Food Res. Int., 34(6), 461-471. https://doi.org/10.1016/S0963-9969(01) 00070-9

Fang, Y., Sheng, J. C., Xu, J., An, X., Hu, Q. (2007). Antioxidant activities of crude tea polyphenols, polysaccharides and proteins of selenium-enriched tea and regular green tea. Eur. Food Res. Technol., 225(5-6), 843-848. https://doi.org/10.1007/s00217-006-0490-y

Gül, D. A., Gokay, O., Arzu, M., Kivrak, T. C., Tavana, A. M. (2017). Effect of various teas on color stability of resin composites. Am. J. D., 30(6), 323-328.

GB/T 16291.1 (2012). Sensory analysis - General guidance for the selection, training and monitoring of assessors Part 1: Selected assessors. China, National standard of the people's Republic of China.

GB 7101 (2015). Beverage. China, National standard of the people's Republic of China.

GB 4789.2 (2016). Food microbiological analysis Colony count determination. China, National standard of the people's Republic of China. 
Liu, Y., Ding, X., Zheng, L. X., Zhang, Y., Zhou, H. (2020). Herbal drink formulation optimization of Trollius chinensis Bunge by sensory fuzzy comprehensive evaluation. Acta Sci. Pol. Technol. Aliment., 19(2), 185-194. http://dx.doi.org/10.17306/J.AFS.2020.0776

GB 4789.3 (2016). Food microbiological analysis Coliform count determination. China, National standard of the people's Republic of China.

Guo, L., Qiao, S., Hu, Li, D., Zheng, S., Shi, D., Liu, J., Wang, R. (2017). Investigation of the effective components of the flowers of Trollius chinensis from the perspectives of intestinal bacterial transformation and intestinal absorption. Pharm. Biol., 57(1), 1747-1758. https://doi.org/10.1080/13880209.2017.1321023

Hmar, B. Z., Mishra, S., Pradhan, R. C. (2017). Physicochemical and sensory analysis of kendu (Diospyros melaxoxylon Roxb.) jam using fuzzy logic. J Food Meas. Charact., 11(4), 1928-1935. https://doi.org/10.1007/ s11694-017-9575-5

Hu, Z., Wang, P., Zhou, H., Li, Y. (2018). Extraction, characterization and in vitro antioxidant activity of polysaccharides from Carex meyeriana Kunth using different methods. Int. J. Biol. Macromol., 120, 2155-2164.https:// doi.org/10.1016/j.ijbiomac.2018.09.125

Ioannou, I., Perrot, N., Hossenlopp, J., Mauris, G., Trystram, G. (2002). The fuzzy set theory: a helpful tool for the estimation of sensory properties of crusting sausage appearance by a single expert. Food Qual. Prefer., 13(7-8), 589-595. https://doi.org/10.1016/s09503293(02)00045-9

ISO 8589 (1988). Sensory analysis; general guidance for the design of test rooms.

Lam, K. Y., Ling, A. P., Koh, R. Y., Wong, Y. P., Say, Y. H. (2016). A review on medicinal properties of orientin. Adv. Pharmacol. Sci., 4104595. https://doi.org/ doi:10.1155/2016/4104595

Li, Y. D., Zhang, T., Xiong, R. X., Zheng, K. X., Zhao, Y. F., Chen, D., ..., Hu, C. J. (2017). Optimization of processing technology of Hemsleya omeiensis by orthogonal design and central-composite design-response surface methodology. Chin. Tradit. Herbal. Drugs, 48(5), 913-917. https://doi.org/10.7501/j.issn.0253-2670.2017.05.012

Li, H. Y., Liu, Y. (2013). Research progress on the extraction, purification and pharmacological of flavonoids in Trollius Chinensis bunge. Appl. Mech. Mater., 295-298, 283-286. https://doi.org/10.4028/www.scientific.net/ AMM.295-298.283

Li, P., Yang, Z., Chen, Y., Zhang, X., Guo, Y. (2014). Extraction optimization and in vitro antioxidant and antiviral activities of crude polysaccharides from Mentha haplocalyx. Food Sci. Techn., 39(12), 196-201. https://doi. org/10.13684/j.cnki.spkj.2014.12.042

Lieb, V. M., Esquivel, P., Castillo, E. C., Carle, R., Steingass, C. B. (2018). Gc-ms profiling, descriptive sensory analysis, and consumer acceptance of costa rican papaya
(Carica papaya L.) fruit purees. Food Chem., 248, 238246. https://doi.org/10.1016/j.foodchem.2017.12.027

Liu, Y., Sui, X., Zhou, H., Ma, X., Liu, Y. (2012). Study on extraction technology of crude polysaccharide from Trollius in Greater Khingan Mountains. J. Jilin Inst. Chem. Technol., 29(9), 51-54. https://doi.org/10.3969/j. issn.1007-2853.2012.09.014

Liu, J. Y., Li, S. Y., Feng, J. Y., Sun, Y., Cai, J. N., Sun, X. F., Yang, S. L. (2013). Flavone $C$-glycosides from the flowers of Trollius chinensis and their anti-complementary activity. J. Asian Nat. Prod. Res., 15(4), 325-331. https://doi.org/10.1080/10286020.2012.760545

Lu, J., Qin, P.-Z., Han, X., Wang, Y.-P., Li, Z.-H. (2014). Evaluation of antioxidant and antibacterial properties of extracts from Trollius chinensis Bunge. Eur. Food Res. Technol., 240(2), 301-310. https://doi.org/10.1007/ s00217-014-2329-2

Muir, D. D. (2007). Sensory evaluation techniques. Int. J. Dairy Technol., 60(4), 305-305. https://doi.org/10.1111/ j.1471-0307.2007.00330.x

Mukhopadhyay, S., Majumdar, G. C., Goswami, T. K., Mishra, H. N. (2013). Fuzzy logic (similarity analysis) approach for sensory evaluation of chhana podo. LWT - Food Sci. Techn., 53(1), 204-210. https://doi. org/10.1016/j.lwt.2013.01.013

Sakre, N., Das, A. B., Srivastav, P. P. (2015). Fuzzy logic approach for process optimization of gluten-free pasta. J. Food Proc. Pres., 40(5), 840-849. https://doi. org/10.1111/jfpp. 12662

Sinija, V. R., Mishra, H. N. (2011). Fuzzy analysis of sensory data for quality evaluation and ranking of instant green tea powder and granules. Food Bioproc. Technol., 4(3), 408-416. https://doi.org/10.1007/s11947-008-0163-x

Skelton, M. (1984). Sensory evaluation of food. Cornell Hospit. Quart., 24(4), 51-57. https://doi.org/10.1177/00 1088048402400413

Wang, J. P., Chen, Z. Y. (2008). Effects of different extraction and purification techniques on total flavonoids content in trollflower. J. Chengde Med. Coll., 25, 356-359.

Witkowska-Banaszczak, E. (2015). The genus Trollius - review of pharmacological and chemical research. Phytother. Res., 29(4), 475-500. https://doi.org/10.1002/ ptr.5277

Yan, R., Cui, Y., Deng, B., Bi, J., Zhang, G. (2019). Flavonoid glucosides from the flowers of Trollius chinensis Bunge. J. Nat. Med., 73(1), 297-302. https://doi. org/10.1007/s11418-018-1263-1

You, X., Wang, L., Sun, Y., Li, W. (2014). The extraction process optimization of glycyrrhizin. Food Indus., 35(5), 95-97.

Zhang, D. F., Ye, M., Deng, M. C. (2016). Development of Trollius chinensis and licorice compound instant tea. Food Indus., 37(12), 11-14. 